\title{
Neurological Manifestations of Congenital \\ Cytomegalovirus Infection at a Tertiary Care Centre from Southern India
}

\author{
Vykuntaraju K. Gowda ${ }^{1, \odot ~ P r e e t i ~ K u l h a l l i ² ~ D h a n a n j a y a ~ K . ~ V a m y a n m a n e ~}{ }^{3}$
}

${ }^{1}$ Department of Pediatric Neurology, Indira Gandhi Institute of Child health, Bengaluru, Karnataka, India

2Department of Pediatrics, Karnataka Institute of Medical Sciences, Hubballi, Karnataka, India

${ }^{3}$ Department of Radiology, Indira Gandhi Institute of Child health, Bengaluru, Karnataka, India

J Neurosci Rural Pract:2021;12:133-136

\author{
Address for correspondence Vykuntaraju K. Gowda, DM,, \\ Department of Pediatric Neurology, Indira Gandhi Institute of \\ Child health, Near NIMHANS, Bengaluru, Karnataka 560029, India \\ (e-mail: drknvraju08@gmail.com).
}

\begin{abstract}
Background Cytomegalovirus (CMV) is a ubiquitous herpes virus. It is the most common congenital viral infection. Data on congenital CMV in India are lacking and hence the present study was undertaken.

Objectives The aim of the study is to evaluate the clinical and radiological profile of neurological manifestations of congenital CMV infections in tertiary care hospital.

Methods This is a retrospective chart review of the clinical and laboratory profile of congenital CMV infections presenting from January 2018 to February 2020 to a tertiary care hospital in Southern India. Details of clinical profile, serological and neuroimaging data were obtained and analyzed.

Results A total of 42 cases with female preponderance (57\%) were reported during the study period. The mean age of presentation was 2.9 years. Clinical features were developmental delay (81\%), microcephaly (93\%), seizures (33\%), intrauterine growth restriction (19\%), neonatal encephalopathy (10\%), anemia (9\%), jaundice (10\%), hepato-splenomegaly (7\%), and eye abnormalities (14\%). Antenatal maternal fever was reported by $12 \%$. Sensorineural hearing loss was present in $57 \%$. Neuroimaging showed periventricular calcification (79\%), cerebral atrophy (69\%), ventricular dilatation (55\%), malformations (26\%), dysmyelination (12\%), and temporal lobe cysts (5\%). CMV-immunoglobulin-M positivity was seen in 14 cases (33\%), urinary polymerase chain reaction for $\mathrm{CMV}$ was positive in 21 cases (50\%), and clinical diagnosis was done

Keywords

- cytomegalovirus

- congenital

- developmental delay

- India

- central nervous system in seven cases (16\%).

Conclusion Common findings in congenital CMV are microcephaly, developmental delay, seizures, anemia, and sensorineural hearing loss. Common neuroimaging findings are periventricular calcification, cerebral atrophy, malformation, white matter signal changes, and cysts. CMV can mimic like cerebral palsy, malformations of the brain, demyelinating disorders, and calcified leukoencephalopathies like Aicardi-Goutières syndrome.
\end{abstract}

DOI https://doi.org/

10.1055/s-0040-1721557

ISSN 0976-3147. (c) 2021. Association for Helping Neurosurgical Sick People.

This is an open access article published by Thieme under the terms of the Creative Commons Attribution-NonDerivative-NonCommercial-License, permitting copying and reproduction so long as the original work is given appropriate credit. Contents may not be used for commercial purposes, or adapted, remixed, transformed or built upon. (https://creativecommons.org/licenses/by-nc-nd/4.0/)

Thieme Medical and Scientific Publishers Pvt. Ltd., A-12, 2nd Floor, Sector 2, Noida-201301 UP, India 


\section{Introduction}

Cytomegalovirus (CMV) is an omnipresent herpesvirus. It spreads by close contact through saliva, blood, breast milk, genital secretions, or urine. It has been seen to infect up to $90 \%$ of the United States population. It remains latent in monocytes and granulocytes for the lifetime. ${ }^{1-3}$ Yearly approximately 20,000 to 40,000 infants in the United States are born with congenital CMV infection, corresponding to an incidence of 0.6 to $0.7 \%$ of deliveries, thus, making CMV the most common congenital viral infection. ${ }^{4-7}$ In various serological surveys in India, an incidence of 80 to $90 \%$ seropositivity with CMV IgG is shown in mothers. ${ }^{8}$ However, data regarding the frequency and various neurological manifestation of congenital CMV from India are lacking and commonly mistaken for other neurological disorders. The overall incidence of congenital CMV ranges from 0.5 to $3.0 \%$ in all live births. ${ }^{9}$ Most children (approximately $85-90 \%$ ) do not have clinical findings at birth (asymptomatic CMV infection). ${ }^{10,11}$ The CMV infection, can present with symptoms in the newborn period or with long-term neurodevelopmental sequelae. According to two large meta-analyses, congenital CMV presented symptomatically in 11 to $12.7 \%$ of all neonates. ${ }^{4,5}$ Some prospective studies have shown that approximately half of the children born with asymptomatic infection will develop sensorineural hearing loss (SNHL), intellectual disability with intelligence quotient less than 70, and microcephaly. ${ }^{4,12}$ Congenital CMV infection is commonly mistaken for other causes of developmental delay like cerebral palsy, leukodystrophies, and malformations. Hence, it becomes important to estimate the neurological (both clinical and radiological) key points which will aid early diagnosis, treatment, and rehabilitation to prevent morbidity and mortality. The present study was undertaken with objectives to estimate the neurological (both clinical and radiological) profile of congenital CMV-infected cases in a tertiary care hospital in South India.

\section{Methods}

This was a retrospective chart review of the clinical and radiological profile of children with congenital CMV infection, presenting to a tertiary care hospital in South India from January 2018 to February 2020. Children aged between day one and 18 years were included. Congenital CMV was defined as IgM (immunoglobulin $\mathrm{M}$ ) positive status for $\mathrm{CMV}$, and/or urinary CMV positive status by polymerase chain reaction (PCR) method and those with clinically suspected static encephalopathies with CT scan (computed tomography) showing periventricular calcification after ruling out other secondary causes, were included in the study. Data regarding the age of presentation, sex, presenting complaint, consanguinity, family, birth, and developmental history, and examination findings were recorded from computer-based data. Relevant investigations that were done were noted. The laboratory investigations for CMV by IgM titers and urinary PCR were documented. Neuroimaging with magnetic resonance imaging (MRI) brain/
CT brain/ultrasonography (USG) cranium was traced. In the absence of any information, parents were contacted telephonically and history, investigations collected. Data were collected on a predesigned pretested proforma, analyzed, and presented in frequencies. Ethical clearance was obtained from the Institutional Ethical Committee.

\section{Results}

Forty-two cases from January 2018 to February 2020 were included in the study aged between day one and 18 years. Various clinical features are shown in - Table 1. Mean age at presentation was 2.9 years. Female preponderance was present with females being $57 \%$, and female to male ratio of $1.3: 1$. Consanguinity was seen in $19 \%$ of the cases. Serological markers showed, CMV-IgM positivity in 14 cases (33.33\%), urinary PCR for CMV was positive in 21 cases (50\%). The clinical diagnosis was done in seven cases (16.66\%).

Neuroimaging was done in all cases. СT brain was done in 15 cases and MRI brain was done in 36 cases. In nine cases both CT and MRI were done, as the initial CT scan was

Table 1 Clinical features of congenital cytomegalovirus infections

\begin{tabular}{|c|c|}
\hline Parameter & $\begin{array}{l}\text { Frequency in figures } \\
\text { (percentages) }\end{array}$ \\
\hline Maternal fever with rash & $05(11.90)$ \\
\hline $\begin{array}{l}\text { Intra uterine growth retardation } \\
\text { (IUGR) babies }\end{array}$ & $08(19.04)$ \\
\hline Neonatal encephalopathy & $04(09.52)$ \\
\hline Neonatal pneumonitis & $01(02.38)$ \\
\hline Developmental delay & 34 (80.95) \\
\hline Seizures & $14(33.33)$ \\
\hline Generalized & $09(21.42)$ \\
\hline Myoclonic jerks & $03(07.14)$ \\
\hline Focal seizures & $02(04.76)$ \\
\hline Dysmorphism & $07(16.60)$ \\
\hline Microcephaly & $39(92.85)$ \\
\hline Skin rashes: petechiae/purpura & $03(07.14)$ \\
\hline Anemia & $38(90.47)$ \\
\hline Jaundice & $04(09.52)$ \\
\hline Pyramidal signs & 34 (80.95) \\
\hline Hemiplegia & $04(09.52)$ \\
\hline Hepatosplenomegaly & $03(07.14)$ \\
\hline Ocular abnormality & $06(14.02)$ \\
\hline Strabismus & $03(07.14)$ \\
\hline Cataracts & $02(04.76)$ \\
\hline Chorioretinitis & $01(02.38)$ \\
\hline Sensorineural hearing loss & $24(57.14)$ \\
\hline Bilateral & $16(38.09)$ \\
\hline Left & $03(07.14)$ \\
\hline Right & 05 (11.90) \\
\hline
\end{tabular}

Abbreviation: IUGR, intra uterine growth retardation 
Table 2 Neuroimaging findings of CT scan and MRI of brain

\begin{tabular}{|l|l|}
\hline Finding on imaging & Frequency (percentages) \\
\hline Periventricular calcification & $33(78.57)$ \\
\hline Ventricular dilatation & $23(54.76)$ \\
\hline Cortical atrophy & $29(69.04)$ \\
\hline Migration abnormality & $11(26.19)$ \\
\hline Pachygyria/agyria & $06(14.28)$ \\
\hline Lissencephaly & $05(11.80)$ \\
\hline Dysmyelination & $05(11.90)$ \\
\hline Temporal lobe cysts & $02(04.76)$ \\
\hline Cerebellar hypoplasia & $02(04.76)$ \\
\hline
\end{tabular}

Abbreviations: $\mathrm{CT}$, computed tomography; MRI, magnetic resonance imaging.

normal, and strong clinical suspicion of central nervous system involvement entailed a further MRI. The details are summarized in - Table 2. Periventricular leukomalacia and cerebral atrophy were commonest findings.

\section{Discussion}

CMV infection is the most common cause of congenital viral infection in the Western world affecting 0.5 to $2.4 \%$ of newborns. Neurological signs include cognitive, motor impairments, SNHL, and chorioretinitis. ${ }^{13,14}$ Neuroimaging is a useful aid in diagnosis in older children in whom serology and PCR can be normal. ${ }^{15}$ In this retrospective review of 42 cases, the mean age of presentation was 2.9 years, with a female preponderance. Millichap et al reported a mean age of 20 months at presentation. ${ }^{16}$ The commonest mode of presentation was a developmental delay with pyramidal signs, as seen in $80.95 \%$ of the cases. This finding was much higher than the results of $10 \%$ as seen by Preece et al, Hanshaw and Dudgeon, and Reynolds et al. ${ }^{17-19}$ Ninety percent of these children had cerebral palsy in a study by Boesch et al. ${ }^{20}$ Seizures were seen in $33.33 \%$ of the cases, which was similar to Millichap et al, who reported $37 \%$ seizure incidence. ${ }^{16}$ The maternal febrile illness was seen in $12 \%$, in contrast to $54.8 \%$ as seen by Munro et al. ${ }^{21}$ The incidence of intrauterine growth restriction (IUGR) was 19\%, which contrasted with a study done by Boppana et al where incidence was documented in $50 \%$ of the infants. ${ }^{22}$ Microcephaly was seen in $93 \%$ of children, whereas Boppana et al and Bale Jr et al deduced 53 and 70\% incidence in their studies, respectively. ${ }^{22,23}$ Skin lesions like purpura/petechiae were seen in $7 \%$ of the cases. However, it was a major finding of up to $76 \%$ in a study by Boppana et al.22

Anemia was a common finding in our study (90\%), which was similar to Pemde et al, where anemia was documented in $89 \%$ of children. ${ }^{24}$ Incidence of jaundice and hepatosplenomegaly was 9 and $7 \%$, respectively. The incidence of jaundice and hepatosplenomegaly was 22 and $66 \%$, respectively in a study by Gandhoke et al. ${ }^{8}$ Ocular abnormalities in the form of strabismus, bilateral cataracts, and chorioretinitis were noted in $14 \%$ of children. This was similar to a study done by Coats et al, where ocular abnormalities were seen in $22 \%$ of the cases, but predominant causes were optic atrophy, macular scars, and cortical visual impairment. Strabismus was seen in $29 \%$ of their cases. ${ }^{25}$ SNHL was seen in $57 \%$ of children in our study. The incidence of SNHL is reported to vary from 9 to $50 \% .{ }^{17}$ Up to $30 \%$ rate of SNHL is seen in symptomatic infants at birth. ${ }^{26}$ Bernard et al showed hearing abnormalities in $92 \%$ of the cases, bilateral in $33 \%$ and partial with unilateral in $23 \%{ }^{27}$

Neuroimaging showed periventricular calcification to be the most common finding followed by cerebral atrophy, ventricular dilatation, migration abnormalities in the form of polymicrogyria/agyria and lissencephaly. Dysmyelination, temporal lobe cysts, and cerebellar hypoplasia were fewer common findings. Manara et al found white matter changes to be the commonest followed by ventriculomegaly in $64 \%$, migration disorders in $43 \%$, hippocampal dysplasia in $43 \%$, and cerebellar hypoplasia in $28 \%{ }^{28}$ Dilated lateral ventricles (100\%) and subarachnoid space (80\%), oligo/pachygyria (80\%), delayed myelination (70\%), periventricular cysts $(60 \%)$, and intracerebral calcification in $10 \%$ were findings in a study by Boesch et al..$^{20}$

The limitations of this study are that it is retrospective in nature and confirmatory tests like CMV IgM antibody and PCR cannot be done in all children due to late presentation because of which both can be false negative. However, this is the largest study in this decade that shows that CMV continues to be a common problem in India and can present to neurologists with various clinical and radiological features that can be mistaken for various other neurological conditions.

\section{Conclusion}

Clinically, congenital CMV can present with global developmental delay, low birth weight, neonatal cholestasis, microcephaly, seizures, anemia, visual problems like cataract and chorioretinitis, SNHL, and hepatosplenomegaly. Radiologically congenital CMV infection should be considered in cases of bilateral periventricular and basal ganglia calcifications, white matter signal changes mimicking leukodystrophies, calcified cystic leukoencephalopathy especially in case of temporal and frontal lobe cysts, and malformation of the brain with associated calcifications.

\section{Authors' Contributions}

V. K. W. contributed toward supervision, guidance, and the review of the manuscript. P. K. was involved in the management of the child and the preparation of manuscript. D. K. V. has given valuable inputs in the management of this child.

\section{Funding}

None.

\section{Conflict of Interest}

None declared. 


\section{References}

1 Staras SA, Dollard SC, Radford KW, Flanders WD, Pass RF, Cannon MJ. Seroprevalence of cytomegalovirus infection in the United States, 1988-1994. Clin Infect Dis 2006;43(9): 1143-1151

2 Kondo K, Xu J, Mocarski ES. Human cytomegalovirus latent gene expression in granulocyte-macrophage progenitors in culture and in seropositive individuals. Proc Natl Acad Sci U S A 1996;93(20):11137-11142

3 Hargett D, Shenk TE. Experimental human cytomegalovirus latency in CD14+ monocytes. Proc Natl Acad Sci U S A 2010;107(46):20039-20044

4 Dollard SC, Grosse SD, Ross DS. New estimates of the prevalence of neurological and sensory sequelae and mortality associated with congenital cytomegalovirus infection. Rev Med Virol 2007;17(5):355-363

5 Kenneson A, Cannon MJ. Review and meta-analysis of the epidemiology of congenital cytomegalovirus (CMV) infection. Rev Med Virol 2007;17(4):253-276

6 Nyholm JL, Schleiss MR. Prevention of maternal cytomegalovirus infection: current status and future prospects. Int J Womens Health 2010;2:23-35

7 Leung AK, Sauve RS, Davies HD. Congenital cytomegalovirus infection. J Natl Med Assoc 2003;95(3):213-218

8 Gandhoke I, Aggarwal R, Lal S, Khare S. Congenital CMV infection in symptomatic infants in Delhi and surrounding areas. Indian J Pediatr 2006;73(12):1095-1097

9 Britt WJ, Cytomegalovirus. In: Remington JS, Klein JO, Wilson CB, Nizet V, Maldonado Y, eds. Infectious Diseases of the Fetus and Newborn Infant. Philadelphia: Elsevier Saunders; 2011: 706-755

10 Townsend CL, Forsgren M, Ahlfors K, Ivarsson SA, Tookey PA, Peckham CS. Long-term outcomes of congenital cytomegalovirus infection in Sweden and the United Kingdom. Clin Infect Dis 2013;56(9):1232-1239

11 Williamson WD, Desmond MM, LaFevers N, Taber LH, Catlin FI, Weaver TG. Symptomatic congenital cytomegalovirus. Disorders of language, learning, and hearing. Am J Dis Child 1982;136(10):902-905

12 Boppana SB, Pass RF, Britt WJ, Stagno S, Alford CA. Symptomatic congenital cytomegalovirus infection: neonatal morbidity and mortality. Pediatr Infect Dis J 1992;11(2):93-99

13 Ivarsson SA, Lernmark B, Svanberg L. Ten-year clinical, developmental, and intellectual follow-up of children with congenital cytomegalovirus infection without neurologic symptoms at one year of age. Pediatrics 1997;99(6):800-803
14 Pass RF, Stagno S, Myers GJ, Alford CA. Outcome of symptomatic congenital cytomegalovirus infection: results of long-term longitudinal follow-up. Pediatrics 1980;66(5):758-762

15 Boppana SB, Fowler KB, Vaid Y, et al. Neuroradiographic findings in the newborn period and long-term outcome in children with symptomatic congenital cytomegalovirus infection. Pediatrics 1997;99(3):409-414

16 Millichap JG. Congenital cytomegalovirus infection and risk of epilepsy. Pediatr Neurol Briefs 2008;22(6):46

17 Preece PM, Pearl KN, Peckham CS. Congenital cytomegalovirus infection. Arch Dis Child 1984;59(12):1120-1126

18 Hanshaw JB, Dudgeon JA. Congenital cytomegalovirus. Major Probl Clin Pediatr 1978;17:97-152

19 Reynolds DW, Stagno S, Stubbs KG, et al. Inapparent congenital cytomegalovirus infection with elevated cord IgM levels. Casual relation with auditory and mental deficiency. N Engl J Med 1974;290(6):291-296

20 Boesch C, Issakainen J, Kewitz G, Kikinis R, Martin E, Boltshauser E. Magnetic resonance imaging of the brain in congenital cytomegalovirus infection. Pediatr Radiol 1989;19(2): 91-93

21 Munro SC, Trincado D, Hall B, Rawlinson WD. Symptomatic infant characteristics of congenital cytomegalovirus disease in Australia. J Paediatr Child Health 2005;41(8):449-452

22 Boppana SB, Ross SA, Fowler KB. Congenital cytomegalovirus infection: clinical outcome. Clin Infect Dis 2013;57(suppl 4): S178-S181

23 Bale JF Jr, Bray PF, Bell WE. Neuroradiographic abnormalities in congenital cytomegalovirus infection. Pediatr Neurol 1985; $1(1): 42-47$

24 Pemde HK, Kabra SK, Agarwal R, Jain Y, Seth V. Hematological manifestations of congenital cytomegalovirus infection. Indian J Pediatr 1995;62(4):473-477

25 Coats DK, Demmler GJ, Paysse EA, Du LT, Libby C. Ophthalmologic findings in children with congenital cytomegalovirus infection. J AAPOS 2000;4(2):110-116

26 Cowles TA, Gonik B, Cytomegalovirus. In: Fanaroff AA, Martin RJ, eds. Neonatal-Perinatal Medicure: Diseases of the Fetus and Infant. St. Louis: Mosby; 1997:337-338

27 Bernard S, Wiener-Vacher S, Van Den Abbeele T, Teissier N. Vestibular disorders in children with congenital cytomegalovirus infection. Pediatrics 2015;136(4):e887-e895

28 Manara R, Balao L, Baracchini C, Drigo P, D'Elia R, Ruga EM. Brain magnetic resonance findings in symptomatic congenital cytomegalovirus infection. Pediatr Radiol 2011;41(8):962-970 